\title{
A poesia de Daniel Faria: a claridade da morte
}

IDA FerReira Alves

Universidade Federal Fluminense

RESUMO: APRESENTA-SE, AQUI, A OBRA DE DANIEL FARIA, POETA QUE OCUPOU LUGAR ÍMPAR NA POESIA PORTUGUESA CONTEMPORÂNEA, TENDO FALECIDO EM 1999, AOS 28 ANOS. ANÁLISE DE SUA ESCRITA EM RELAÇÃO À TENSÃO ENTRE O HUMANO E O SAGRADO, ENTRE A PALAVRA COMUM, COTIDIANA, E A PALAVRA ESSENCIAL DA POESIA. ABORDA-SE TAMBÉM A FORÇA DO TEMA DA MORTE COMO UMA QUESTÃO FUNDAMENTAL DA LINGUAGEM, O ESPAÇO LIMITE DA PALAVRA POÉTICA A PARTIR DA PERSPECTIVA DE MAURICE BLANCHOT.

ABSTRACT: IT IS ABOUT PRESENTING THE WORK OF DANIEL FARIA, A POET THAT OCCUPIED AN UNIQUE PLACE IN CONTEMPORARY PORTUGUESE POETRY, WHO DIED IN 1999, BEING 28 YEARS OLD. ANALYSIS OF HIS WRITING ACCORDING TO THE TENSION BETWEEN THE HUMAN AND THE SACRED, BETWEEN THE COMMON EVERYDAY WORD AND THE ESSENTIAL WORD OF POETRY. IT ALSO DEALS WITH THE POWER OF THE DEATH'S THEME AS A FUNDAMENTAL QUESTION OF LANGUAGE, THE LIMIT SPACE OF POETIC WORD, ACCORDING TO THE PERSPECTIVE OF MAURICE BLANCHOT.

PALAVRAS-CHAVE: POESIA PORTUGUESA CONTEMPORÂNEA - DANIEL FARIA - LIRISMO E MORTE - LINGUAGEM POÉTICA E SILÊNCIO

KEY-WORDS: CONTEMPORARY PORTUGUESE POETRY - DANIEL FARIA - LYRISM AND DEATH - POETIC LANGUAGE AND SILENCE 
oubesse eu estilhaçar a noite. Soubesse eu morrer

Iluminando

(FARLA, 2003: 302)

No âmbito do grupo de pesquisa "Máscaras de Perséfone: Figurações da Morte nas Literaturas Portuguesa e Brasileira Contemporâneas", sediado na PUC-MG e coordenado pela Profa. Dra. Lélia Parreira Duarte, temos colaborado com a reflexão contínua sobre o texto poético. Para isso, falamos da poesia portuguesa do século XX, que pode ser caracterizada de modo amplo por sua diversidade e qualidade. Não são poucos os nomes de poetas que ficarão no tempo representando essa poesia, como os de Jorge de Sena, Sophia de Mello Breyner Andresen, Eugénio de Andrade, António Ramos Rosa, Ruy Belo e Herberto Helder, para citar apenas alguns. Neste artigo, porém, desejamos destacar somente um poeta dos anos 90 que, em pouco tempo e com obra pouco extensa, conseguiu marcar o seu lugar de diferença no contexto da poesia portuguesa da segunda metade do século passado.

Os leitores habituais dessa poesia sabem bem que, a partir dos anos 60, quando se iniciou de forma mais sistemática a discussão sobre mudanças diversas em vários níveis do pensamento social, político, econômico, ideológico e cultural contemporâneo, o que daria azo à formulação de questões sobre uma pós-modernidade, definiu-se na produção poética portuguesa, de um lado, uma prática de determinados processos líricos em torno da impessoalidade, da afirmação da depuração extrema do verso e da objetualidade do poema, com as experiências visuais e concretistas, e, de outro, ganhou voz a reivindicação de alguns jovens poetas de 70 em torno da idéia de um "regresso ao sentido", da afirmação do sujeito, da narratividade do cotidiano sem esquecer também outras trilhas independentes ${ }^{1}$. Também nos anos 80 e 90, afirmar-seia a poesia de Adília Lopes, que surge em edições de autor e torna-se, por um certo tempo, o acontecimento pop do circuito literário português ${ }^{2}$. Já no início

\footnotetext{
1 Sobre essas trilhas, há que se verificar a produção crítica de dois poetas fundamentais desse momento: Gastão Cruz e Joaquim Manuel Magalhães. O primeiro, autor de A poesia portuguesa hoje, 1972, com segunda edição de 1999; o segundo, autor de Os dois crepuisculos - sobre poesia portuguesa actual e outras crónicas, 1981.

2 Mas, hoje, passada a efervescência de sua presença no cenário poético português, Adília, podemos dizer, é uma voz poética com reconhecimento crítico e com produção integrada ao movimento poético do final do século XX.
} 
do século XXI, essa defesa de um "regresso ao real" voltaria a alimentar uma polêmica em torno da constituição de uma nova poesia portuguesa, questão provocada pelo prefácio de uma antologia intitulada "poetas sem qualidades", que seriam aqueles descrentes do sublime, da alta cultura, da poesia de lirismo acentuado e de forte imaginário cultural, autores apenas de uma poesia do cotidiano, do banal, da linguagem rarefeita, dos efeitos líricos pseudobiográficos e dessublimantes. Miguel de Freitas, poeta que assinava o prefácio com tom de manifesto, afirmava o direito dessa poesia a não ter qualidades, a não continuar uma tradição intelectual, metafísica e erudita de poesia. Naturalmente, essas formas e formulações poéticas divergentes são questionamentos contemporâneos da subjetividade, e experiências do lírico num tempo de acentuada fragmentação do sujeito e desconstrução de tradições.

Por isso, em face desse contexto polifacetado, chamou a atenção da crítica portuguesa um jovem poeta que escrevia na contramão, com apenas seis livros publicados - Uma cidade com muralha (1992), Oxálida (1992), A casa dos ceifeiros (1993), Explicação das árvores e de outros animais (1997), Homens que são como lugares mal situados (1998) e Dos líquidos (2000) - e obra encerrada inesperadamente. Falamos de Daniel Faria, poeta nascido em 1971 e que vem a falecer em 1999, após um acidente doméstico (uma queda), com 28 anos, quando estava quase a terminar o noviciado no Mosteiro Beneditino de Singeverga ${ }^{4}$. Uma vida muito curta que, no entanto, deixou uma produção poética a chamar a atenção pelo seu modo outro de compreender o lirismo e a palavra poética. Em 2003, a editora portuguesa "Quasi” publicou a reunião dos livros de poesia de Daniel Faria, juntando 13 poemas inéditos, edição da qual retiramos os poemas aqui citados.

O leitor atento de sua obra logo percebe quais são as opções líricas feitas. Afastado da poesia que caracterizaria, em geral, os poetas de sua idade, afastado das trilhas de uma poesia do cotidiano ou da provocação adiliana ou dos "sem qualidades", Daniel Faria é um poeta dos anos 90 muito mais próximo de poetas de uma tradição ontológica, sejam eles os paradigmáticos Hölderlin

\footnotetext{
3 A respeito da polêmica, cf. ALVES, 2006, p. 217-227.

4 Daniel Faria freqüentou o curso de Teologia na Universidade Católica Portuguesa, Porto, tendo defendido, em 1996, tese de licenciatura intitulada A meditação da paixão na poesia de Frei Agostinho da Cruz. Também se licenciou em Estudos Portugueses na Faculdade de Letras da Universidade do Porto, no período de 1994 a 1998. Desde criança manifestou sua atração pela vida religiosa.
} 
e Rilke, sejam os portugueses Ruy Belo e Herberto Helder no que estes têm (ainda que diferentes entre si) de tensionadores da relação entre o humano e o sagrado, entre o mundo presente e comezinho, entre a palavra poética fundadora de mundos e a palavra cotidiana. Assim, na poética de Daniel Faria, alguns tópicos são recorrentes, como o desenraizamento do sujeito, a errância, a busca/desencontro de sentidos, os confrontos entre a fragilidade humana e a unidade divina, com a configuração de uma imagética espiritualista ligada à luz, às transformações interiores e, sem dúvida, à contemplação da morte, como experiência limite do sujeito e da linguagem. Em coerência com essa perspectiva, sua escrita poética também dialoga com outras experiências do lirismo religioso, reflexão do sagrado e da paixão, como os poemas místicos de São João da Cruz e de Santa Teresa de Ávila, para além dos textos bíblicos. Com eles, sua poesia se constrói como um percurso ontológico, tendo como horizonte a crença na divindade e a vivência do sublime religioso. Para isso, sua linguagem fortalece a metáfora, busca a brevidade e a depuração do ritmo e do corte do verso, com surpreendente coesão entre poemas e livros.

Apresentamos sua poesia sem pretensão de uma hermenêutica teológica, necessária para compreendê-la em maior extensão, mas que foge às nossas possibilidades de análise. Não podemos explicar a totalidade dessa obra, mas errar com ela, porque é antes de tudo de deslocamentos, de errâncias, de paisagens abertas que o poeta fala. Por isso, nossa proposta é considerar alguns poemas como marcos de um percurso, degraus de uma escada para o alto, ou simplesmente casas móveis habitadas por um sujeito lírico que transforma o escrever na experiência mística da transubstanciação: palavra - sangue, palavra - corpo, uma experiência mortal, portanto, como transformação e revelação. Mas, ao lado dessa trilha cristocêntrica, podemos compreender em sua poesia a figuração da morte como uma questão de linguagem, a palavra poética como espaço limite, como risco de existência, como fronteira entre o desconhecimento e a revelação, num processo contínuo de busca e de perda, um sacrifício permanente do sujeito para habitar de outra forma este mundo que é uma construção de palavras.

Num inédito, o poeta escreve:

Sou gémeo de mim e tudo

O que sou é 


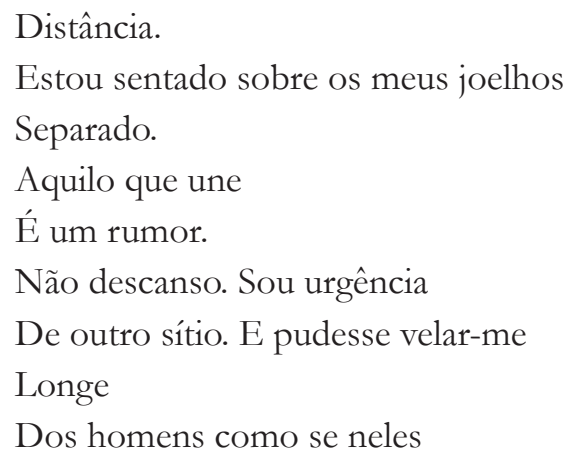

Adormecesse.

(FARIA, 2003: 21)

Anteriormente falamos de paisagens, e se, como explica Michel Collot, a realidade de uma paisagem "n'est accessible qu'à partir d'une perception et/ ou d'une représentation" (COLLOT, 2005: 12), porque é um bem cultural e uma experiência de subjetividade, entendemos ser produtivo percorrer a paisagem que nos apresentam os poemas de Daniel Faria. Sem nomear nenhum referente geográfico, seus versos mostram lugares em aberto, com um olhar para o distante e o invisível. Essa paisagem que é uma experiência íntima do sujeito lírico se mostra marcada por pouquíssimos elementos concretos ou naturais: casa, escada, degraus, pedras, flores, manhã, noite, água, fogo, terra. O sujeito sempre em trânsito, "sou urgência de outro sítio", caminha em busca do que não tem limites nem respostas e se aproxima sempre da morte, como fonte de clarividência, claridade, luz. Se essa paisagem e essa experiência têm contornos nitidamente místicos e cristãos, é também uma experiência de poesia, de linguagem, assim como a de Herberto Helder, que bem poderia assinar os seguintes versos de Faria: "[...] Estou ligeiramente acima do que morre / Nessa encosta onde a palavra é como pão / Um pouco na palma da mão que divide / E não separo como o silêncio em meio do que escrevo // Ando ligeiro acima do que digo / E verto o sangue para dentro das palavras / Ando um pouco acima da transfusão do poema” (FARIA, 2003: 39).

A questão de linguagem que Daniel Faria parece perseguir é o silêncio do nome, o inominável, o silêncio-ausência, formas negativas que se transformam em potência, expectativa, revelação. Os elementos da natureza marcam 
seus poemas, mas um deles é a metáfora dessa dualidade e concentração de sentido: a pedra.

A pedra tem a boca junto do ouvido

E para dentro de si mesma sem cessar se diz.

Se cair nos olhos

Quebrar-se-á em pranto.

Se rodar no dorso

Vergar-me-á.

Pesa-me no bolso

E na cabeça.

Não é um pensamento.

É uma ideia ensimesmada. Uma pedra fechada

Pelo lado de dentro.

(FARIA, 2003: 49)

Em outro poema, o poeta diz que "Para dentro / Do nome se esvazia o corpo quando o corpo cai / É um fruto. / / O nome é ainda / O modo como chamas. // O nome é a arma contra mim. O maior perigo. / Com os teus lábios podes destruir-me" (FARIA, 2003: 77). Mais uma vez afirma-se a potência do nome, do verbo, defesa e perigo. A ligação entre linguagem e Deus é aqui extremamente tensionada. A manifestação divina é esse verbo-carne, é esse silêncio pleno que aterroriza e atrai, é o sublime do insondável, do não nomeável. Por isso a poesia se torna para esse poeta um espaço aberto, uma errância, uma entrega total, e um destino mortal: "O meu projecto de morrer é o meu ofício / Esperar é um modo de chegares / Um modo de te amar dentro do tempo" (FARIA, 2003: 85).

Sua escrita de poemas curtos, versos econômicos, palavras naturais, se torna uma paisagem que reflete as parábolas de Cristo: o campo, o arado, os animais, as plantas, o dia, a noite, o trabalho do pastor, do camponês, a semeadura, o concreto da vida humana, a cegueira do homem que não consegue ver Deus, que não consegue entrar no outro lado do mistério da divindade. Um título de seu livro de 1998 diz bem dos "Homens que são como Lugares 
mal situados", por isso a errância é uma missão e um projeto, e a linguagem, uma paisagem que deve se tornar visível, que deve se configurar como espaço aberto para recepção do silêncio, da revelação do outro lado das imagens. Sua poesia que tanto fala de degraus é um processo de aprendizagem, de ascese, um permanente confronto entre presença e ausência, plenitude e vazio, sabedoria e ignorância, conhecimento e desconhecimento.

Homens que são como lugares mal situados

Homens que são como casas saqueadas

Que são como sítios fora dos mapas

Como pedras fora do chão

Como crianças órfãs

Homens agitados sem bússola onde repousem

Homens que são como fronteiras invadidas

Que são como caminhos barricados

Homens que querem passar pelos atalhos sufocados

Homens sulfatados por todos os destinos

Desempregados das suas vidas

Homens que são como a negação das estratégias

Que são como os esconderijos dos contrabandistas

Homens encarcerados abrindo-se com facas

Homens que são como danos irreparáveis

Homens que são sobreviventes vivos

Homens que são sítios desviados

Do lugar

(FARIA, 2003: 124)

Naturalmente, a poética de Daniel Faria nos recorda o platonismo cristão e o terror do homem enclausurado quando se defronta com a luz da verdade. Para superar esse terror, o caminho que o poema nos ensina é o amor, como experiência de falta/presença, como experiência órfica. "[...] // Repito a corrida na memória quando estou parado / Penso velozmente que o amor, como 
Dante disse, é um estado / De locomoção. É um motor. E fico a trabalho no mecanismo secreto / Do amor. / / Sei que estou em viagem na palavra que se move" (FARIA, 2003: 132).

Assim, essa poética que convida a uma leitura religiosa torna-se também uma erótica da linguagem. O jovem poeta coloca-se, por essa perspectiva, ao lado de poetas como Herberto Helder e Luísa Neto Jorge ${ }^{5}$, poetas que penetram na linguagem como corpos amantes, como carne que se abre e sangra. "Falo daquilo que vejo, embora possas pensar que sou cego / seguindo as mãos - sim, toco as palavras nas suas superfícies / e utensílios. // [...] / / Sim, agora vejo que falo, embora possas pensar que sigo pelo tacto a escrita. / Sim, eu leio e decifro. E agora sei que oiço as coisas devagar" (FARIA, 2003: 174).

Não é a morte, afinal, a imagem fundamental da poética de Daniel Faria, mas o silêncio, e o poema é o seu instrumento de execução. O poeta, aquele que toca o corpo do poema, aquele que trabalha no seu limite: "[...] E trago todos os instrumentos na circulação do sangue e na ocupação permanente / Das mãos / Para o instrumento difícil / Do silêncio" (FARIA, 2003: 181).

O último livro do poeta, póstumo - Dos líquidos (2000) -, é considerado pela crítica portuguesa sua obra maior. Nele estão presentes as fortes linhas de toda a sua trajetória poética: a matriz religiosa, o desejo de ascese, a entrega sacrificial pela palavra em busca da metamorfose, a idéia de centro como morte. O livro divide-se em sete partes: "Das nascentes", "Dos líquidos", "Do inesgotável", "Do sangue", "Das inúmeras águas", "Do que sangro" e "Do ciclo das intempéries". Esse imaginário líquido separado em águas de purificação e águas sombrias (sangue) reflete o processo de sacrifício, de entrega, em busca da transubstanciação da palavra-água em carne-corpo do poema. Com referências explícitas a diversos textos bíblicos, esse último livro é uma construção que dá a ver no texto o abismo da criação.

Essa poética parece ainda dialogar com a busca ininterrupta blanchotiana que se afasta da noite para chegar a outra noite da linguagem. E o diálogo se estabelece independentemente da epiderme cristã de sua escrita, porque há no seu interior algo mais tensionado: a relação entre sujeito e linguagem, se

\footnotetext{
5 Daniel Faria era leitor atento de Luísa Neto Jorge, segundo comentários daqueles que conviveram com o poeta (MOURA, 2003). Também em sua poesia muitas são as marcas vindas de Luísa, especialmente nos poemas da parte "Do ciclo das intempéries", do livro Dos líquidos.
} 
esta é, como pensou Heidegger, a morada do ser. Em sua poesia o sujeito lírico é simultaneamente um ser de palavras e de silêncio, e é por meio dessa junção que se torna possível a nomeação do inominável. A linguagem poética problematiza assim o indizível, o invisível e torna-se um trajeto em busca da luz, fogo, lume:

Sem outra palavra para mantimento

Sem outra força onde gerar a voz

Escada entre o poço que cavaste em mim e a sede

Que cavaste no meu canto, amo-te

Sou cítara para tocar as tuas mãos.

Podes dizer-me de um fôlego

Frase em silêncio

Homem que visitas

Ó seiva aspergindo as partículas do fogo

O lume em toda a casa e na paisagem

Fora da casa

Pedra do edifício aonde encontro

A porta para entrar

Candelabro que me vens cegando.

Sol

Que quando és nocturno ando

Com a noite em minhas mãos para ter luz.

(FARIA, 2003: 240)

Há na poesia de Daniel Faria a certeza da fé, mas o que queremos destacar aqui é a necessidade da crença na palavra poética. Essa crença poética se faz mais forte em face da dúvida do nome, da possibilidade do fracasso do sentido, da precariedade e fragilidade do ser. A figuração da morte se faz assim, em sua poética, como o espaço intervalar ou de ausência, de vazio, de silêncio, que o poeta luta por penetrar ("Há os que se deitam sobre a relva / Como sombras que dormem sobre túmulos / Tu, porém, dormes sobre a morte / A longa ausência que há dentro dos poemas" (FARIA: 2003: 399). É importante notar que o TU muitas vezes presente em seus versos não só figura Aquele que submeteu a morte, mas também Aquele que para sempre 
tornou-se pleno na ausência. Dessa forma, sua poética une espaços diferentes de leitura e reflete no espiritual a concretude da linguagem. Nessa direção, escreveu Luis Adriano Carlos:

Esta aliança do abstracto e do concreto acaba por fazer convergir teologia e poesia numa rigorosa finalidade estética que traduz a manifestação sensível da idéia. [...] Se os homens são lugares mal situados, é poeticamente que eles habitam esta terra, como pretendia Hölderlin, e só o verso devotado a um destino estético poderá re-situá-los num lugar em que a representação coincida com a Unidade e o Sentido. O homem é um pensamento encadeado no metro da linguagem, tropo do espírito que se ergue infinitamente da queda radical, por isso o seu lugar não é senão a possibilidade criadora de mudar de lugar. (CARLOS, 2006)

E o poeta:

Trabalho a partir da existência da luz

E de certos minerais

Mesmo se não mereço a matéria luminosa

Da terra soprada donde o homem vem. A ânfora, o vidro. E recolho

O fogo

Quando como no princípio a manhã se abeira

Trabalho a partir da ceifa matinal. Experimento

A paveia antiga do homem vergado, o rumor enxugado do líquido

$\mathrm{Na}$ névoa, no orvalho, na carne

Da palavra calculando o voo

Pelo reflexo sobre as águas: no início

Trabalho na água que a voz movimentou

Gerando os sismos: e sou

O húmus, o barro nas margens

$\mathrm{O}$ homem que nunca compreendeu

(FARIA, 2003: 265) 
Essa crença dá a Daniel Faria um lugar ímpar na poesia portuguesa mais contemporânea, porque, em sentido contrário aos dos seus pares, não defende o regresso ao real, ao legível, mas o regresso à metáfora, como metamorfose e conhecimento. Em oposição a uma poesia do concreto, do cotidiano, do banal, do biográfico, sua escrita defende a visão interior e uma outra experiência de mundo: "Escrevo do lado mais invisível das imagens / Na parede de dentro da escrita e penso / Erguer à altura da visão o candeeiro / Branco da palavra com as mãos / [...] / Grito-lhe: imaginai o que nunca tivestes nas mãos / / Correi. Como o segador seguindo o segador / Numa ceifa terrestre, tombando. Digo: / Imaginai” (FARIA, 2003: 271). Sobre esse último verso, Alcir Pécora, em análise "close reading" desse poema, conclui: "Eis aqui refigurada na morte do corpo fatigado, a força pura da palavra cuja melhor imagem é a da aniquilação. É sobretudo na imaginação da morte que repousa a escrita da palavra invisível [...]" (PÉCORA, 2002: 85).

Finalmente, mais uma vez lembramos Herberto Helder para dizer que, como esse poeta que deslocou, na contemporaneidade, todos os lugares estáveis da poesia portuguesa, Daniel Faria transforma o poema em corpo errante e a escrita num projeto de paixão. Queremos defender, então, que o jovem poeta dos anos 90 recupera uma tradição maior da lírica portuguesa, que é a experiência do amor como experiência limite do ser/da linguagem, a energia propulsora da máquina do mundo camoniana, em que Eros e Tanatos se misturam na medida humana refigurada no canto de Orfeu, canto do sujeito dilacerado pela perda amorosa, cujo corpo se torna a memória da morte, quando o ser está ao "desabrigo completo".

Eu peneiro o espírito e crivo o ritmo

Do sangue no amor, o movimento para fora

O desabrigo completo. Penetro os múltiplos

Sentidos da palavra que sopra a sua voz

Nos pulsos. Crivo a pulsação do canto

E encontro

O silêncio inigualável de quem escuta

Eis porque as minhas entranhas vibram de modo igual Ao da cítara 
Eu peneiro as entranhas e encontro a dor

De quem toca a cítara. A frágil raiz

De quem criva horas e horas a vida e encontra

A corda mais azul, a veia inesgotável

De quem ama

Encontro o silêncio nas entranhas de quem canta

Eis porque o amor vibra no espírito de quem criva

O músico incompleto peneira a ideia das formas

Eu sopro a água viva. Crivo

O sofrimento demorado do canto

Encontro o mistério

Da cítara

(FARIA, 2003: 280)

A poesia como canto errante, como canto não da plenitude, mas da falta, da ânsia, e por isso contínuo, permanente. Como lemos também em Herberto Helder (2006): "Escrever não mostra o que fica, mas o que falta. Para tocar o fundo. Disso se morre, de escrita. Mas nada vale senão morrer. O sentido revelador disto está em que tudo desaparece com cada um. Morre-se para que o mundo morra, e crime e culpa se dissolvam, como se a escrita - morte alheia e própria - fosse uma espécie de exasperada, misteriosa e emblemática regeneração”.

\section{Referências Bibliográficas}

ALVES, Ida Ferreira. Os poetas sem qualidades na poesia portuguesa recente. In: PEDROSA, Celia; CAMARGO, Maria Lucia de Barros. Poéticas do olhar e outras leituras de poesia. Rio de Janeiro: 7 Letras, 2006. p. 217-227.

BLANCHOT, Maurice. A obra e o espaço da morte. In: O espaço literário. Rio de Janeiro: Rocco, 1987. p. 81-160.

CANTINHO, Maria João. Daniel Faria ou a (im)possibilidade de uma arqueologia da palavra. Disponível em: <www.storm-magazine.com>. Acesso em: 20 fev. 2007.

CARLOS, Luis Adriano. A poesia de Daniel Faria. Disponível em: <www.letras.up.pt/ deper/primeiraprova/apdf.htm>. Acesso em: 25 out. 2006. 
COLLOT, Michel. Paysage et poésie du romantismo à nos jours. Paris: José Corti, 2005.

CRUZ, Gastão. A poesia portuguesa hoje. 2. ed. corrig. e aum. Lisboa: Relógio d’Água, 1999.

FARIA, Daniel. <www.danielfaria.org> [página oficial do poeta]. Poesia. Vila Nova de Famalicão: Quase, 2003.

HELDER, Herberto. Photomaton \&o vox. 4. ed. Lisboa: 2006.

LOPES, Silvina Rodrigues. Literatura, defesa do atrito. Lisboa: Vendaval, 2003.

MAGALHÃES, Joaquim Manuel. Os dois crepúsculos - sobre poesia portuguesa actual e outras crónicas. Lisboa: A Regra do Jogo, 1981.

MOURA, Vítor. O giroscópio. Revista Relâmpago. Lisboa: Fundação Luís Miguel Nava, n. 12, p. 53-61, abr. 2003.

NUNES, José Ricardo. Daniel Faria. In: . 9 poetas para o século XXI. Coimbra: Angelus Novus, 200, p. 17-30.

PÉCORA, Alcir. Escrevo do lado mais invisível das imagens. In: SILVESTRE, Osvaldo Manuel; SERRA, Pedro (org.). Século de ouro - antologia crítica da poesia portuguesa do século XX. Braga/Coimbra: Angelus Novus \& Cotovia, 2002. p. 80-85. 